\title{
Balance Calculation and Optimization of Denitrification Process Simulation of Oxy-fuel Combustion Flue Gas
}

\author{
Qiang HUANG \\ Jiujiang University, JiuJiang 332005, Jiangxi, China \\ hq_hust@163.com
}

Keywords: Oxy-fuel combustion, Denitrification, Equilibrium calculation, Optimization analysis.

\begin{abstract}
Oxy-fuel combustion is an important development direction of combustion technology, and the key technology to reduce the cost of flue gas purification is the reduction of denitration cost. Based on the experiments and simulation process with Aspen Plus of pressure denitrification process, the reaction time and equilibrium concentration were analyzed when the denitrification reaction was balanced. Finally, the denitrification process was optimized according to the simulation results. The results showed that the equilibrium concentration and time of the denitrification process decreased with the increase of pressure, initial oxygen content and the decrease of temperature. The content of NO in flue gas had little influence on equilibrium concentration and time. After analysis and calculation, it is considered that $30^{\circ} \mathrm{C}$ and 26 bar is more suitable for denitrification process of the pressurized flue gas.
\end{abstract}

\section{Introduction}

Oxy-fuel combustion technology is also called $\mathrm{CO}_{2} / \mathrm{O}_{2}$ cycle combustion technology. It has good continuity with traditional coal-fired power generation technology in technology and workmanship. Economic evaluation also shows that oxy-fuel combustion technology is most competitive on equipment investment cost and generation cost compared with the same kind of technology now. This combustion mode has become one of the most important development direction of coal combustion technology in this century[1,2].

In oxy-fuel combustion process, oxygen separation from air and $\mathrm{CO}_{2}$ compression will cost greater energy consumption which will increase the cost of electricity generation greatly. Therefore, reducing the cost of power generation by various means faces a significant challenge. And reducing the cost of flue gas purification is one of the most important ways. The desulfurization cost of coal-fired power plants is low, and the cost of denitrification is very high. So reducing the denitration cost of oxy-fuel combustion is very importance to reduce the cost of flue gas purification[3,4].

For this purpose, the process of single denitrification in compression process is studied. Based on the experimental results of the pressure denitrification process, simulation process is built by using Aspen Plus. Effects of pressure, temperature, initial oxygen concentration, initial NO concentration and the presence of $\mathrm{N}_{2}$ in flue gas on the pressure denitrification process is systematically analyzed. In this paper, the reaction time and equilibrium concentration are analyzed when the system reaction reached equilibrium. Finally, the pressure denitrification process is optimized according to the simulation results. The rationality and feasibility of this mechanism are further proved.

\section{Model of Pressure Denitrification and Result Analysis}

Firstly, the pressure denitrification experiments are carried out under some conditions on the experiment bench. The experiment gas is a mixture of $\mathrm{NO}, \mathrm{SO}_{2}$ and $\mathrm{CO}_{2}$. The experiment conditions and results are shown in Table 1. Then according to the experiment process and conditions, the Aspen Plus process simulation is performed. The established Aspen Plus process is shown in Fig.1.

According to the above experiment equipment and conditions, a series of Rbatch modules are simulated based on the dynamics principle. Rbatch1 simulates $\mathrm{CO}_{2}$ cleaning process. Rbatch2 simulates flue gas pressure boosting. Rbatch3 simulates constant pressure reaction process. The 
export mixture carries out flash separation and dehydration at the end of the reaction[6,7]. Then the gas composition is analyzed to study the denitration rate of the denitration process.

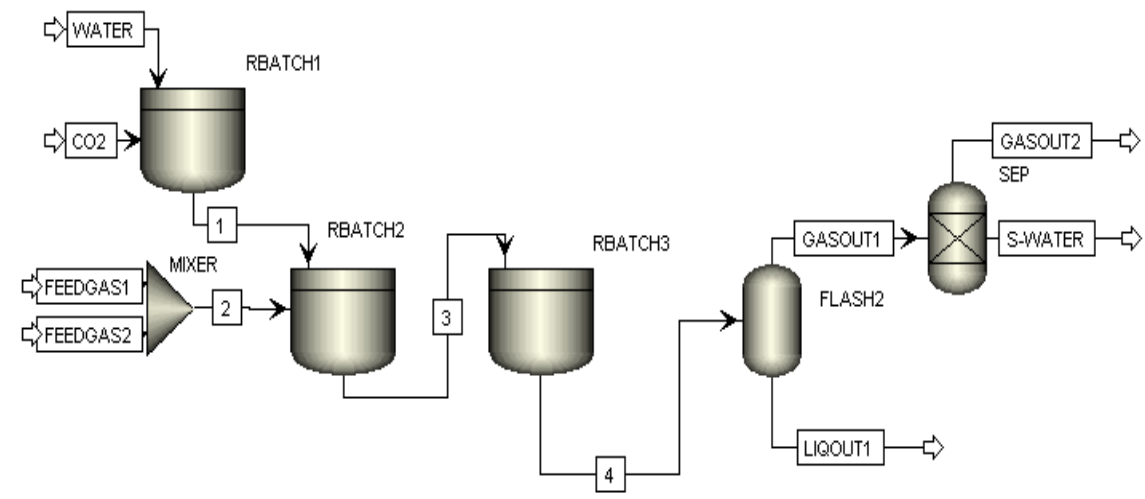

Fig.1 Flow chart of pressurized denitrification of oxy-fuel combustion flue gas

Ensured that the simulation process is the same as the flue gas and operating conditions of the experiment process, the experiment research and Aspen process simulation of pressure denitrification under different conditions are carried out in the reactor. The conditions of denitrification, the conditions and results of experiment and simulation are shown in Table 1.

Table 1. Comparison of simulation and experimental results

\begin{tabular}{|c|c|c|c|c|c|c|c|}
\hline \multicolumn{2}{|c|}{ Initial concentration } & \multirow{2}{*}{$\begin{array}{c}\text { Temperature } \\
/^{\circ} \mathrm{C}\end{array}$} & \multirow{2}{*}{$\begin{array}{l}\text { Pressure } \\
\text { /bar }\end{array}$} & \multirow{2}{*}{$\begin{array}{l}\text { Residence } \\
\text { time /min }\end{array}$} & \multirow{2}{*}{$\begin{array}{l}\text { Simulated NO } \\
\text { removal rate } / \%\end{array}$} & \multirow{2}{*}{$\begin{array}{l}\text { Experimental NO } \\
\text { removal rate } \%\end{array}$} & \multirow{2}{*}{$\begin{array}{l}\text { relative } \\
\text { error/\% }\end{array}$} \\
\hline $\mathrm{NO} / p p m$ & $\mathrm{O}_{2} / \%$ & & & & & & \\
\hline 279 & 5 & 25 & 10 & 5 & 76.0 & 76.0 & 0 \\
\hline 836 & 5 & 25 & 6 & 5 & 83.5 & 82.7 & 1.0 \\
\hline 836 & 5 & 25 & 10 & 5 & 92.5 & 92.2 & 0.3 \\
\hline 836 & 5 & 25 & 10 & 10 & 95.9 & 95.2 & 0.7 \\
\hline 836 & 5 & 30 & 10 & 5 & 91.1 & 91.0 & 0.1 \\
\hline 836 & 10 & 25 & 10 & 5 & 94.4 & 93.5 & 1.0 \\
\hline 836 & 5 & 25 & 14 & 5 & 94.9 & 95.3 & -0.4 \\
\hline
\end{tabular}

As shown in Table 1, by comparing the experiment and simulation results, the NO removal rate is in good agreement with the data. The maximum relative error is only $1 \%$. It shows that the model and mechanism used in simulation are reliable and feasible.

\section{Balance Simulation of Pressure Denitrification Process}

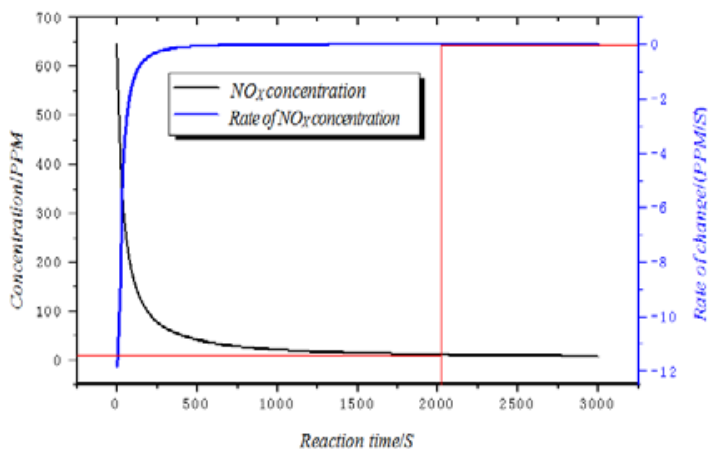

Fig.2 Relationship between NOx and change rate with reaction time under $10 \mathrm{bar}$

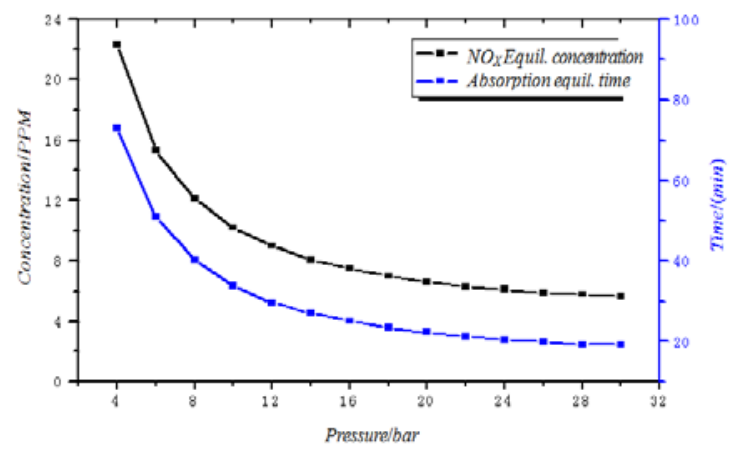

Fig.3 Effect of pressure on NO absorption equilibrium time and concentration

In order to consider the economical efficiency, when the reaction reaches equilibrium, the required time and $\mathrm{NO}_{\mathrm{X}}$ concentration are discussed under various reaction conditions. Assumed the change rate of $\mathrm{NO}_{\mathrm{X}}$ concentration is less than 0.005, the reaction reached equilibrium. As shown in Fig.2, under 10bar condition, the change rate of $\mathrm{NO}_{\mathrm{X}}$ concentration with time is obtained by differential 
calculus of this change. When the change rate of $\mathrm{NO}_{\mathrm{X}}$ concentration with the time is less than 0.005 , we consider that the reaction has reached equilibrium. The time and $\mathrm{NO}_{\mathrm{X}}$ concentration are the equilibrium time and concentration of the reaction.

By keeping the same simulation condition and increasing the constant pressure reaction time of the simulation process, the relationship between $\mathrm{NO}_{\mathrm{X}}$ concentration and time is analyzed. Using the analysis method of Fig.2, effects of absorption pressure, absorption temperature, initial oxygen concentration and initial NO concentration on equilibrium time and concentration are analyzed systematically.

\section{Effect of Pressure on No Absorption Equilibrium Time and Concentration}

The reactor temperature is $25^{\circ} \mathrm{C}$, oxygen concentration is $5 \%$ and initial NO concentration is $836 \mathrm{ppm}$ in mixture 2. By changing the stopping pressure in Rbatch2, and increasing the constant pressure reaction time, effect of pressure on NO absorption equilibrium time and concentration is studied. The pressure range is 4bar to 30bar, and results of the simulation are shown in Fig.3.

As shown in Fig.3, the $\mathrm{NO}_{\mathrm{X}}$ equilibrium concentration and time decrease gradually with the increase of pressure. When the pressure is low, the concentration and time of $\mathrm{NO}_{\mathrm{X}}$ decrease obviously. When the pressure is high, they reduce gradually. It is obviously that increase of pressure can reduce the $\mathrm{NO}_{\mathrm{X}}$ absorption equilibrium time. But when the pressure is too high, it will increase the compression work of denitration process and investment in equipment (especially the acid corrosion).

\section{Effect of Temperature on No Absorption Equilibrium Time and Concentration}

The stopping pressure in Rbatch2 is 10bar, oxygen concentration is $5 \%$, and initial NO concentration is 836ppm in mixture 2. By changing the absorption reactor temperature and increasing the reaction time of absorption process, effect of temperature on $\mathrm{NO}$ absorption equilibrium time and concentration is studied. The range of temperature is $10^{\circ} \mathrm{C}$ to $85^{\circ} \mathrm{C}$, and results of the simulation are shown in Fig.4.

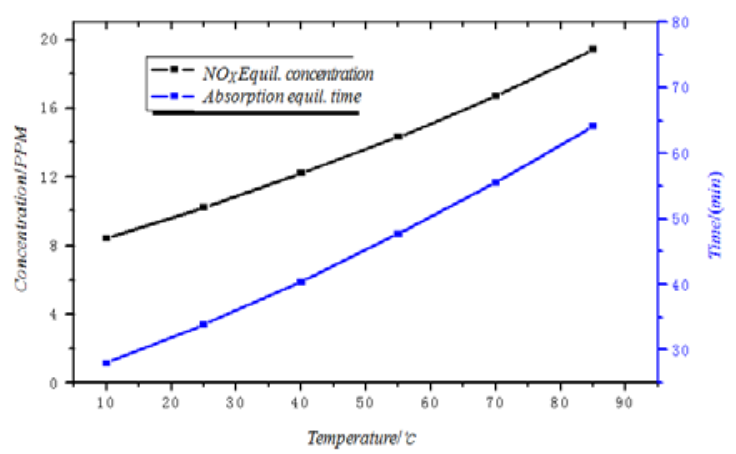

Fig.4 Effect of temperature on NO absorption on NO equilibrium time and concentration

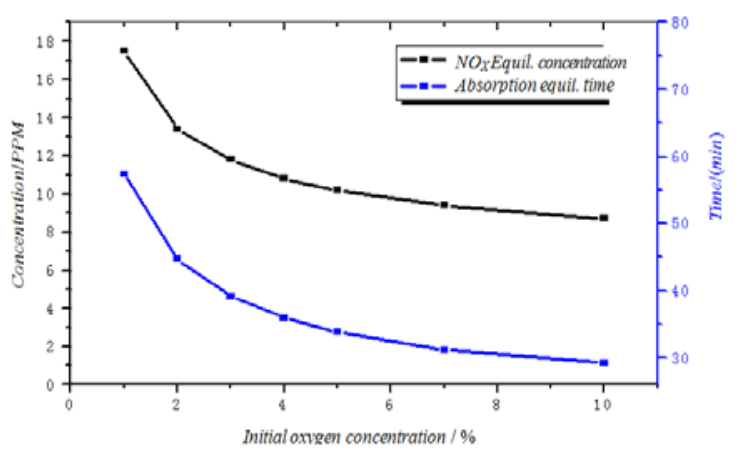

Fig.5 Effect of initial oxygen concentration absorption equilibrium time and concentration

As shown in Fig.4, the $\mathrm{NO}_{\mathrm{X}}$ equilibrium concentration and time increase almost linearly with the increase of temperature. When the temperature is $10^{\circ} \mathrm{C}$, the absorption equilibrium concentration is $8.4 \mathrm{ppm}$, and the absorption equilibrium time is $1681 \mathrm{~S}$. When the temperature increases to $85^{\circ} \mathrm{C}$, the absorption equilibrium concentration is $19.4 \mathrm{ppm}$, and the absorption equilibrium time is $3852 \mathrm{~S}$. It shows that increase of temperature has a great effect on the $\mathrm{NO}_{\mathrm{X}}$ equilibrium concentration and time. It is unfavorable to reduce $\mathrm{NO}_{\mathrm{X}}$ equilibrium concentration and time. But increase of temperature can reduce the energy consumption of flue gas condensation.

\section{Effect of Initial Oxygen Concentration on NO Absorption Equilibrium Time and Concentration}

The stopping pressure in Rbatch2 is $10 \mathrm{bar}$, reactor temperature is $25^{\circ} \mathrm{C}$, and initial NO concentration is 836ppm in mixture 2. By changing the oxygen concentration in mixture 2 and increasing the 
reaction time of absorption process, effect of initial oxygen concentration on NO absorption equilibrium time and concentration is studied. Initial oxygen concentration range is $1 \%$ to $10 \%$, and results of the simulation are shown in Fig.5.

As shown in Fig.5, the $\mathrm{NO}_{\mathrm{X}}$ equilibrium concentration and time decrease gradually with the increase of initial oxygen concentration. It shows that increase of initial oxygen content can reduce $\mathrm{NO}_{\mathrm{X}}$ equilibrium concentration and time. When the initial oxygen content is $1 \%$ to $3 \%$, oxygen content has a great effect on $\mathrm{NO}_{\mathrm{X}}$ equilibrium concentration and time. When the initial oxygen content is greater than $5 \%$, the increase of it has little effect. Therefore, the $3 \%-5 \%$ initial oxygen is more suitable for the denitrification process.

\section{Effect of Initial NO Concentration on NO Absorption Equilibrium Time and Concentration}

The stopping pressure in Rbatch2 is 10bar, oxygen concentration in mixture 2 is $5 \%$, and reactor temperature is $25^{\circ} \mathrm{C}$. By changing the NO concentration in mixture 2 and increasing the reaction time of absorption process, effect of initial oxygen concentration on NO absorption equilibrium time and concentration is studied. Concentration range of NO concentration 165ppm to 950ppm, and results of the simulation are shown in Fig.6.

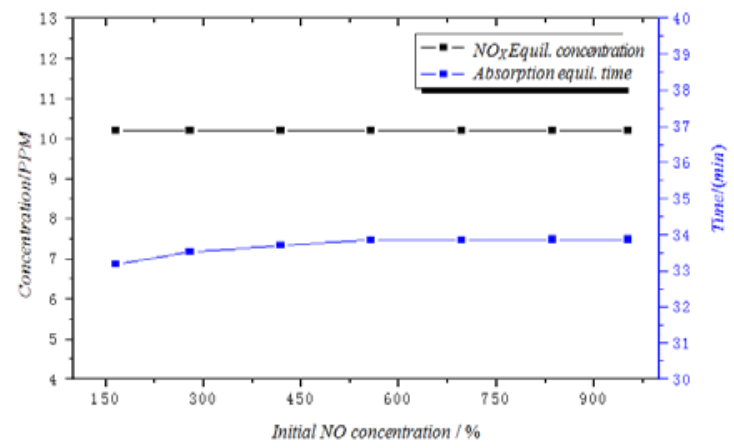

Fig.6 Effect of initial NO concentration on NO absorption equilibrium time and concentration

As shown in Fig.6, the $\mathrm{NO}_{\mathrm{X}}$ equilibrium concentration is almost unchanged with the increase of initial $\mathrm{NO}$ concentration. The $\mathrm{NO}_{\mathrm{X}}$ equilibration time increases slightly and it happens almost at low initial NO concentration. During the initial NO concentration change from 165ppm to 950ppm, the equilibrium time of absorption increases only 40S. Thus, increase of initial NO concentration has almost no effect on the $\mathrm{NO}_{\mathrm{X}}$ equilibrium time and concentration. Although oxy-fuel combustion can significantly reduce $\mathrm{NO}_{\mathrm{X}}$ emissions, but because of the flue gas recirculation, the $\mathrm{NO}_{\mathrm{X}}$ concentration remains high in flue gas even higher than that under air combustion. Therefore, the pressure denitrification process is more suitable for oxy-fuel combustion.

\section{Optimization Analysis of Pressure Denitrification Process}

According to above balance calculation, oxygen concentration range of oxy-fuel combustion process is $3 \%$ to $5 \%$. Selected the median value of $4 \%$, the content of $\mathrm{NO}_{\mathrm{X}}$ in the flue gas had little effect on the pressure denitrification process, so the selection of it has no effect. Therefore, the content of NO is set as 850ppm, a typical one. The lower denitrification temperature is more beneficial to the denitrification process of pressurized flue gas. But the temperature is too low, the energy consumption and investment in equipment will increase. Based on the above factors, the room temperature of $30^{\circ} \mathrm{C}$ is more appropriate. Therefore, the choice of pressure during pressurization is critical[8,9].

The pressure of flue gas should be increased before pressure denitrification. If centrifugal compressor is used to compress the flue gas, the power consumption of the compression process is related to exhaust capacity, ambient temperature, pressure ratio, efficiency, and so on. The formula is as follows[10], 


$$
W=\frac{\rho V_{K} R T \ln \left(P_{2} / P_{1}\right)}{3600 \eta_{T} \eta_{M}}
$$

Among: $\rho$, density of flue gas under standard conditions, $\mathrm{kg} / \mathrm{m}^{3} ; V_{K}$, exhaust capacity of air compressor, $\mathrm{m}^{3} / \mathrm{h} ; R$, gas constant, $R=0.278 \mathrm{~kJ} /(\mathrm{kg} \cdot \mathrm{K}) ; T$, ambient temperature, $K$; $P_{2}$, exhaust pressure, $M p a ; P_{1}$, intake pressure, $M p a ; \eta_{T}$, isothermal efficiency of air compressor; $\eta_{M}$, mechanical efficiency.

Because the intake pressure of air compressor is $0.1 \mathrm{Mpa}$, the compression power consumption is proportional to $W$, that is $W=N \ln P_{2}$ ( $N$ is a constant constant). The ratio of compression power consumption increment of 2 bar pressure increased and the amount of $\mathrm{NO}_{\mathrm{X}}$ removal is the power consumption of unit $\mathrm{NO}_{\mathrm{x}}$ removal. This value is used as the ordinate, and the pressure is the abscissa. The curve is drawn as shown in Fig.7.

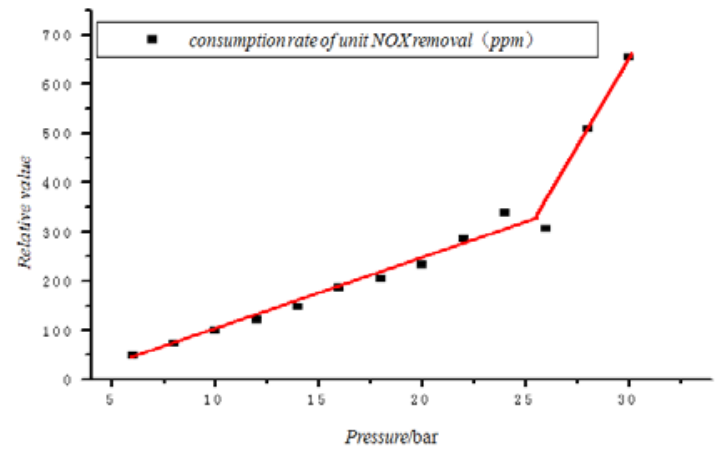

Fig.7 Relationship between pressure and unit power consumption of $\mathrm{NO}_{\mathrm{X}}$ removal

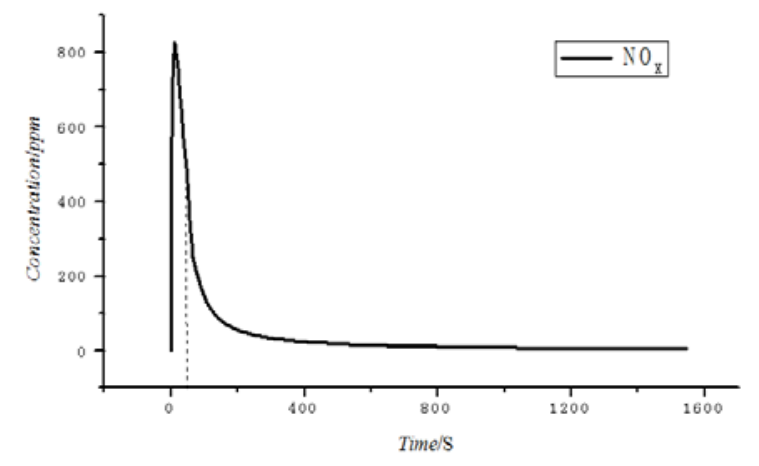

Fig.8 Relationship between $\mathrm{NO}_{\mathrm{X}}$ concentration and time in optimized conditions

As shown in Fig.7, the power consumption rate of $\mathrm{NO}_{\mathrm{X}}$ increases gradually with the increase of pressure. But when the pressure is below 26bar, the consumption rate of unit $\mathrm{NO}_{\mathrm{X}}$ removal increases slowly with the increase of pressure. When the pressure is higher than 26bar, it increases rapidly. So we choose 26bar as the reaction pressure for the pressure denitrification process. Finally, the Aspen Plus process simulation is established according to the optimization conditions. The relationship between the concentration of $\mathrm{NO}_{\mathrm{X}}$ and time is shown in Fig.8.

Simulation results show that $\mathrm{NO}_{\mathrm{X}}$ declines to a great extent at the end of pressure boosting. However, the removal rate of $\mathrm{NO}_{\mathrm{X}}$ is only $43.9 \%$. When the residence time is $147 \mathrm{~S}$, the removal rate of $\mathrm{NO}_{\mathrm{X}}$ can reach $90 \%$. When the residence time is $249 \mathrm{~S}$, the removal rate of $\mathrm{NO}_{\mathrm{X}}$ can reach $95 \%$. When the residence time is $1363 \mathrm{~S}$, the equilibrium concentration is 6.5ppm.

\section{Summary}

With the increase of pressure, initial oxygen content and the decrease of temperature, the equilibrium concentration and time of pressure denitrification decrease gradually. The content of NO in flue gas has little effect on equilibrium concentration and time. Finally, according to analysis and calculation, the temperature of $30^{\circ} \mathrm{C}$ and the pressure of 26bar are more suitable for pressurized flue gas denitrification. Finally, the optimized working condition is obtained under the condition of initial oxygen content of $4 \%$ and initial NO concentration of 850ppm. It indicates that the removal rate of $\mathrm{NO}_{\mathrm{X}}$ is only $43.9 \%$ at the end of pressure boosting. When the residence time is $147 \mathrm{~S}$, the removal rate of $\mathrm{NO}_{\mathrm{X}}$ can reach $90 \%$. When the residence time is $249 \mathrm{~S}$, the removal rate of $\mathrm{NO}_{\mathrm{X}}$ can reach $95 \%$. When the residence time is $1363 \mathrm{~S}$, the equilibrium concentration is 6.5ppm.

\section{Acknowledgement}

This research was financially supported by the National Natural Science Foundation of China (No. 
51566004), the Universities' Sci.\&Tech. Landing Project of Jiangxi Province(No. KJLD14093) and the visiting scholar special funds of development program for middle-aged and young teachers in colleges and universities of Jiangxi Province.

\section{References}

[1] Iman I, CHEN J, Etschamnn B, et al. High-temperature tube corrosion upon the interaction with victorian brown coal fly ash under the oxy-fuel combustion condition[J]. Proceedings of the Combustion Institute. 2017, 36 (3): 3941-3948.

[2] Spero C, Yamada T, Nelson P, et al. Callide Oxyfuel Project: Combustion and Environmental Performance[C]. 3rd Oxyfuel Combustion Conference, Ponferrada Spain, 9-13 September, 2013.

[3] Beyad Y, Burns R, Puxty G, et al. A speciation study of sulfur(IV) in aqueous solution[J]. Dalton Trans. 2014, 43:2147-2152.

[4] Wall T, Stanger R, Liu Y H. Gas cleaning challengers for coal-fired oxy-fuel technology with carbon capture and storge[J]. Fuel, 2011, 108(2013):85-90.

[5] White V, Wright A, Tappe S, et al. The Air ProductsVattenfall Oxyfuel CO2 Compression and Purification Pilot Plant at Schwarze Pumpe[J]. Energy Procedia. 2013, 37:1490-1499.

[6] Ting T, Stanger R, Wall T. Oxyfuel CO2 compression: The gas phase reaction of elemental mercury and NOx at high pressure and absorption into nitric acid[J]. International Journal of Greenhouse Gas Control. 2014, 29:125-134.

[7] Prationo W, Zhang L. Influence of steam on ignition of Victorian brown coal particle stream in oxy-fuel combustion: In-situ diagnosis and transient ignition modelling[J]. Fuel. 2016, 181: 1203-1213.

[8] Stanger R, Ting T, Chris S, et.al. Oxyfuel derived CO2 compression experiments with NOx, SOx and mercury removal-experiments involving compression of slip-streams from the Callide Oxyfuel Project(COP)[J]. International Journal of Greenhouse Gas Control.2015, 41:50-59.

[9] Bhunia S, Sadhukhan AK, Gupta P. Modelling and experimental studies on oxy-fuel combustion of coarse size coal char[J]. Fuel Processing Technology. 2017, 158:73-84.

[10] Fredrik N, Erik J, Tobias P, et al. Nitrogen and sulphur chemistry in pressurised flue gas systems: A comparison of modelling and experiments[J]. International Journal of Greenhouse Gas Control. 2013, 12:26-34. 